\title{
Article
}

\section{A Matrix FMEA Analysis of Variable Delivery Vane Pumps}

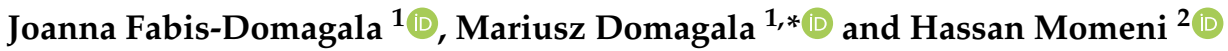 \\ 1 Institute of Applied Informatics, Cracow University of Technology, Al. Jana Pawla II 37, \\ 31-864 Cracow, Poland; joanna.fabis-domagala@pk.edu.pl \\ 2 Department of Mechanical and Marine Engineering, Western Norway University of Applied Sciences, \\ N5020 Bergen, Norway; Hassan.Momeni@hvl.no \\ * Correspondence: domagala@mech.pk.edu.pl
}

\section{check for}

updates

Citation: Fabis-Domagala, J.; Domagala, M.; Momeni, H. A Matrix FMEA Analysis of Variable Delivery Vane Pumps. Energies 2021, 14, 1741. https://doi.org/10.3390/en14061741

Academic Editor: Ryszard Dindorf

Received: 25 February 2021

Accepted: 17 March 2021

Published: 21 March 2021

Publisher's Note: MDPI stays neutral with regard to jurisdictional claims in published maps and institutional affiliations.

Copyright: (c) 2021 by the authors. Licensee MDPI, Basel, Switzerland. This article is an open access article distributed under the terms and conditions of the Creative Commons Attribution (CC BY) license (https:/ / creativecommons.org/licenses/by/ $4.0 /)$.

\begin{abstract}
Hydraulic systems are widely used in the aeronautic, machinery, and energy industries. The functions that these systems perform require high reliability, which can be achieved by examining the causes of possible defects and failures and by taking appropriate preventative measures. One of the most popular methods used to achieve this goal is FMEA (Failure Modes and Effects Analysis), the foundations of which were developed and implemented in the early 1950s. It was systematized in the following years and practically implemented. It has also been standardized and implemented as one of the methods of the International Organization for Standardization (ISO) 9000 series standards on quality assurance and management. Apart from wide application, FMEA has a number of weaknesses, which undoubtedly include risk analysis based on the RPN (Risk Priority Number), which is evaluated as a product of severity, occurrence, and detection. In recent years, the risk analysis has been very often replaced by fuzzy logic. This study proposes the use of matrix analysis and statistical methods for performing simplified RCA (Root Cause Analysis) and for classification potential failures for a variable delivery vane pump. The presented methodology is an extension of matrix FMEA and allows for prioritizing potential failures and their causes in relation to functions performed by pump components, the end effects, and the defined symptoms of failure of the vane pump.
\end{abstract}

Keywords: FMEA; failure analysis; matrix FMEA; vane pump

\section{Introduction}

Due to a high power transmission density, relatively simple movement transformation, and smooth control, hydraulic systems find wide industrial application. Such systems equipped with automation components enable high positioning accuracy and programming movement trajectory. Hydraulic drive systems use accumulated pressure energy of working fluids generated in the hydraulic pump, which is transferred to the receivers by rigid or flexible pipes. This feature creates flexibility, which is unreachable for other systems, and almost unrestricted design capabilities. In addition, compared to purely mechanical systems, any dynamic load can be relatively simply dissipated. The abovementioned advantages make hydraulic systems widely used in drive and control systems in the aeronautic (control systems in airplanes and helicopters), mining, energy (control systems), and automotive industries, which require high reliability and safety. In order to meet these requirements, knowledge about possible failures of such systems as well as their causes is needed. This might be obtained using various methods and tools. Y. Lee et al. [1] carried out an analysis of failures of hydraulic systems used in wind turbines to control pitch blades. The failures of a hydraulic system in wind turbines were also investigated by Y. Lee et al. [2] using Fault Tree Analysis (FTA) and fuzzy logic. Research on the influence of vibrations on hydraulic pipeline failures was conducted by P. Gao et al. [3], while G. Wang et al. [4] studied the influence of failures on shifting quality and driving safety for a continuously variable transmission (CVT) tractor. Research was 
conducted not only for the entire system but also for individual components among which pumps as an energy source are the most critical one. Z. Ma et al. [5] led research on hydraulic pump faults by using a model-based diagnosis system, while T. Li et al. [6] used multiscale information for predicting the remaining useful time of a piston pump. D. Hast et al. [7] also worked on fault specification for the detection of a piston pump fault. C. Lu et al. [8] developed a fault diagnosis method for hydraulic pumps used in aeronautic application based on the evidence theory. Relationships between failure modes and their causes and effects can be developed on the basis of the history of failures and/or using methods of failure analysis among which FMEA (Failure Modes and Effects Analysis) is one of the most successful. There are numerous variations of this method or methods such as fault tree analysis, event tree analysis, or other quality improvement methods and tools [9] that might be used for this purpose. The FMEA fundamental principles found many applications such as RCM (Reliability-Centered Maintenance), hazard analysis, concept FMEA, and FMEDA (Failure Modes, Effects, and Diagnostic Analysis) [10]. RCM is an evolution of FMEA that is used for planning preventive maintenance activity. Increasing demands triggered research on failure predictions and estimation of useful life. It can lead to predicting maintenance plans and, in consequences, achieves the required operation conditions. Fault prognosis methods are not formally classified yet. The work of [11] defined health monitoring systems in a hierarchical structure that uses expert knowledge, physical model, and data driven knowledge. Physical model approaches require an analytical model of the system, while data-driven knowledge approaches define detection and diagnosis as a classification task. The most common tool used in data-driven approaches are neutral network, control charts, and principal component analysis [12]. Another method is presented in Reference [13], in which fault diagnosis and related fault prognosis allow us to estimate the remaining useful life for data available in a normal operation. Research on failures and its causes has been carried out for many years, has found practical application, and was firstly implemented by the US military in 1949: MIL-P 1629 "Procedure for Performing a Failure Modes, Effects and Criticality Analysis" [14]. The next step in the practical implementation of FMEA was done by NASA during the Apollo mission program to estimate the influence of a potential failure on mission success and crew safety. In the next decade, the FMEA was adopted in the automotive industry by one of the largest players: Ford Motor Company. The FMEA was fully formulated and standardized in the 1980s and 1990s in the military standard MIL-STD 1629A, included in the International Organization for Standardization (ISO) 9000 series standards and implemented by SAE J1739 [15]. FMEA supplemented with criticality analysis is known as FMECA (Failure Modes Effect and Criticality Analysis). The FMEDA, for which the foundations were defined in the 1980s, also found practical application, initially in electrical and electronic systems [16]. It supplements the FMEA with two pieces of information: failure rates and the distribution of failure modes, and the ability of detection of failures via an online diagnostic system. It is used as a tool for supporting the IEC61508 standard [17]. The applicability of this method was later extended to electromechanical and mechanical systems [18].

The classic FMEA method has many weaknesses, the most important of which is the use of natural language [19] and erroneous risk estimation using the Risk Priority Number (RPN). Liu HC et al. in $[20,21]$ analyzed the limitations in estimating the risk analysis with the use of RPN. Currently, in the literature, various approaches are used in the evaluation of risk analysis. One of the alternatives is fuzzy logic, which was used by Liu HC et al. [22], S. Bahrebar et al. [23], S. Liu et al. [24], Y. Lv et al. [25], and G. Filo et al. [26]. The weakness of the classical RPN model was also noticed by the industry and recently was replaced by action-priority [27]. In the case of a vane pump, an additional factor that makes evaluation of the probability of a failure detection relatively small is the diagnostic possibilities. During pump operation, they are limited to the measurement of several physical quantities, such as pressure, volumetric flow rate at the pump outlet, and the level of vibration and noise [28]. Additionally, the same symptoms may indicate various types of failures [29]. FMEA uses various tools, one of which is the matrix analysis, which was implemented by G. L. Barbour [30] and M. E. Stock et al. [31] and used in the developed function-failure design 
method. S. G. Arunajadai et al. [32] used the matrix analysis and clustering analysis for failure modes identification. This study proposes a method that is an extension of the method created by G. L. Barbour [30] and combines the aspects of classical FMEA, risk analysis, and RCA [33] by utilization matrix analysis and statistical tools for the failure analysis of a hydraulic vane pump with variable delivery. The presented method can be used in the conceptual, design, or early production stage or in case when expert knowledge base is not available or incomplete. The proposed approach eliminates some of the basic disadvantages of the traditional FMEA and takes into account the relationship between failures and their causes and end effects. It classifies the potential failures and their causes in relation to the importance of individual pump components. This is achieved by matrix transformations. It also allows for classifying potential failures that may occur during pump operation based on the symptoms of pump malfunction by using the Jaccard index [34]. In addition, a practical sheet was developed, which was used to define the necessary data for the analysis.

\section{Research Methodology}

Vane pumps are displacement-types pump in which the displacement chamber is created during shaft rotation between blades, stator, and the covers. An exemplary pump is shown in Figure 1. It is a variable delivery pump by Ponar Wadowice, Poland.

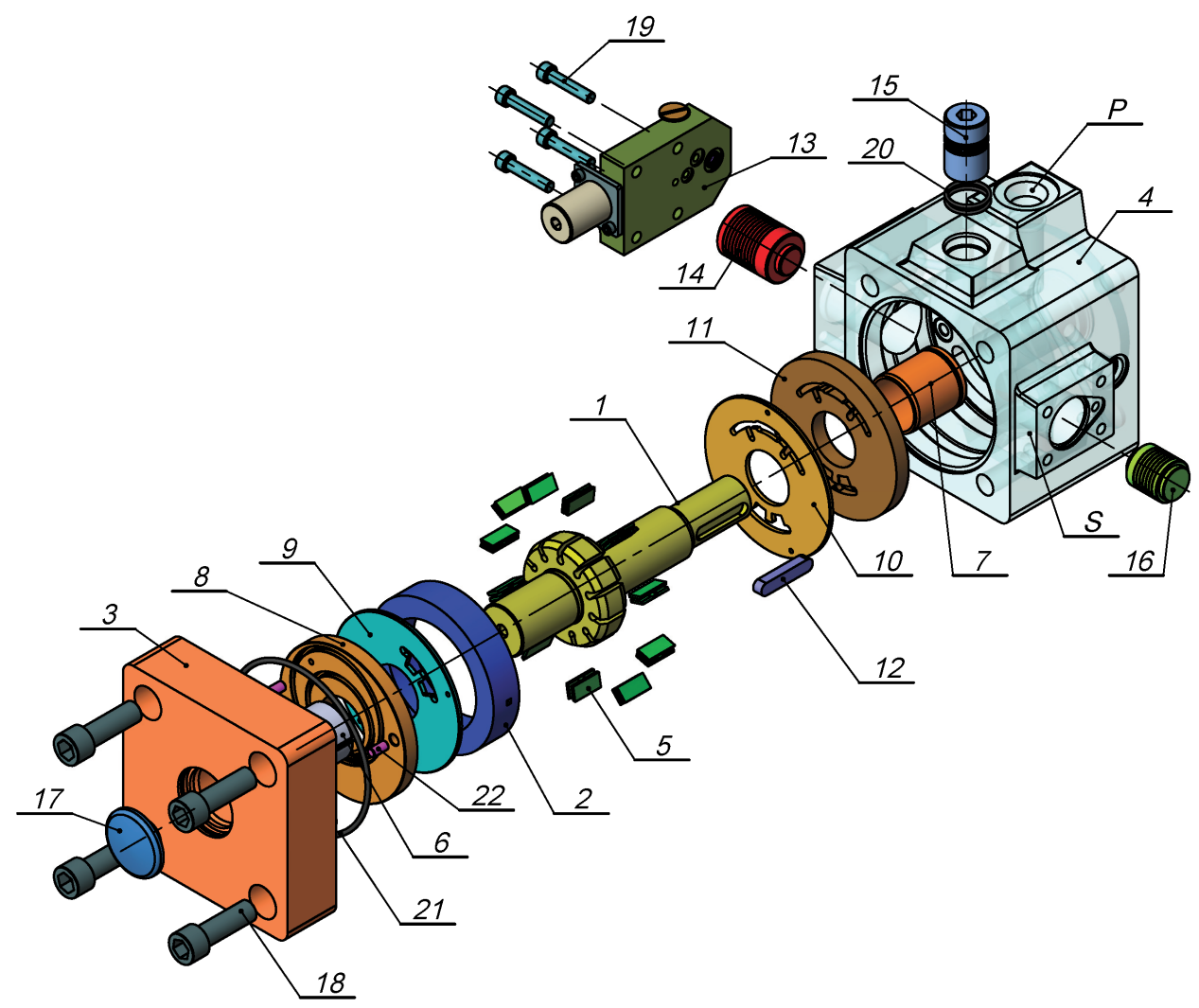

Figure 1. Vane pump: 1-shaft with rotor; 2-stator ring; 3-cover; 4-housing; 5-vanes; 6 and 7-plain bearings; 8-11-port plates; 12-groove key; 13-pressure controller; 14 and 16-control pistons; 15-adjustment screw; 17-plug; 18 and 19-bolts; 20 and 21-sealing rings; 22-pins; $\mathrm{P}$-pressure port; S-supply port (at the bottom of housing).

Two vanes are placed in a single rotor socket, which is made as one part with the shaft. Hydraulic oil is supplied to the displacement chambers through a suction channel in the housing through the side covers. This pump is a double-vane design with relief channels that allow for balancing the pressure on both sides of the vanes and, in consequence, for reducing the frictional forces (vane/stator ring wear) and increasing the pump life time. Pump delivery is set by a regulator that sets the position of the stator via piston. The 
adjusting screw sets the maximal stator eccentricity, which defines the maximal pump delivery. The shaft is mounted on plain bearings in the cover and body, which are bolted together. The drive is transmitted through the key connection on the shaft. The proposed methodology is similar to classic FMEA [35] and consists of the following stages:

1. Main assumptions.

2. Preparation stage.

3. Specification of potential failure modes, and their causes and end effects for individual pump components.

4. Creating sheet.

5. Analysis.

6. Prioritization of failures, and their causes and end effects.

Assumptions.

The main purpose of this study was a qualitative analysis of failure modes, failures and their causes, prioritization of failures, and their causes and end effects. The analysis was carried out only for mechanical systems of the vane pump and without a delivery control system (valve). It was assumed that the analysis would use typical components that occur in vane pumps, not only those presented on Figure 1. In addition, it was assumed that the knowledge base of failures occurring in this type of pump, which may lead to pump malfunction or damage, and the probability of their occurrence is not available. Therefore, potential failures were not prioritized, but their occurrence was only indicated by a binary number system. The same method was used for indicating the cause of failures, the importance of pump components, and end effects. The end effects deal with individual components, not the pump as a whole system. It was assumed that the general form (primary form) of failure would be analyzed (each form of failure may have a variety of different mechanisms).

Preparatory stage.

In the preparatory stage, the pump was decomposed into individual components and their validity was determined based on the functional analysis of the pump. In contrast to the works of [31,33], the functions of the components were determined depending on their impact on the main task of the pump: pumping hydraulic oil to receivers. The following components of vane pumps were used: housing $\left(c_{1}\right)$, cover $\left(c_{2}\right)$, shaft and rotor as one part $\left(c_{3}\right)$, stator $\left(c_{4}\right)$, vane $\left(c_{5}\right)$, port plate $\left(c_{6}\right)$, bearing $\left(c_{7}\right)$, piston $\left(c_{8}\right)$, sealing ring $\left(c_{9}\right)$, pin $\left(c_{10}\right)$, spring $\left(c_{11}\right)$, and fastener $\left(c_{12}\right)$. The abovementioned components were categorized for the following functions:

1. Main function (components that perform the intended function: pumping fluid to receivers) $\left(u_{1}\right)$. The following components were assigned to this function: housing, cover, shaft, stator, vane, and fastener.

2. Auxiliary functions. Components performing these functions ensure proper operation of the pump. Their possible failures may cause the pump malfunction, but the main task of the pump is still maintained $\left(u_{2}\right)$. These components are the port plate, bearing, piston, and sealing ring.

3. Additional components. Their failure has little effect on the main task of the pump $\left(u_{3}\right)$. These elements are the sealing ring, pin, and spring.

In the next step, potential failures that may occur for pump components were identified and classified. We assumed that the knowledge base about vane pump failures is not available; therefore, we used the analogy of failures that occur in typical mechanical systems. It was assumed that the vane pump experiences failures typical of machine shafts, plane and ball bearings, screw connections, sealing components, springs, and pumps (in general). The individual failure might be the result of a chain of several appearing failures, and consequently, determining the cause of the failure is a difficult task. The work of [36] shows examples of failures for which determining the root cause is not straightforward and requires detailed studies. Failure classification is a complex task, and various classification forms are used [37,38]. Donald J. Wulpi [39] defines the following primary 
failures: distortion or undesired deformation: fracture, corrosion, and wear. Wear mechanisms and modes were presented in [40] as mechanical, chemical, and thermal. Potential failures that can occur in vane pumps were classified according to the following mechanisms: fracture and separation, deformation, wear, erosion, corrosion, displacement, and material properties. The following types of failures were selected on the basis of the literature analysis concerning the wear of typical machine shafts [35]: fatigue, corrosion (stress corrosion cracking and corrosion fatigue), abrasive wear (erosion, polishing scratching, and gouging), adhesive wear (scoring, galling, seizing, scuffing, pitting, and fretting), corrosive wear, fretting corrosion, cavitation corrosion, and debris wear. The typical failures of screw connections [36] are fracture (under static load), fatigue, loosening (due to vibration), and corrosion. The typical failures of seals [41] are pattern failure, extrusion, hardening, and damage during installation. The following failures were selected for bearings [36]: deformation (brinelling), fatigue, corrosion (stress corrosion cracking and corrosion fatigue), abrassive wear (erosion, polishing scratching, and gouging), adhesive wear (scoring, galling, seizing, scuffing, pitting, and fretting), corrosive wear, fretting corrosion, cavitation corrosion, and debris wear.

In this study, potential failures were classified based on the wear mechanism in the following way:

1. Fracture and separation: brittle fracture $\left(f_{11}\right)$, fatigue fracture $\left(f_{12}\right)$, pitting $\left(f_{13}\right)$.

2. Deformation: yielding $\left(f_{21}\right)$, extrusion-shrinkage $\left(f_{22}\right)$.

3. Wear: abrasive wear $\left(f_{31}\right)$, adhesive wear $\left(f_{32}\right)$.

4. Erosion: particles erosion $\left(f_{41}\right)$, cavitation erosion $\left(f_{42}\right)$.

5. Corrosion: general corrosion $\left(f_{51}\right)$, chemical attack $\left(f_{52}\right)$.

6. Displacement: loosening $\left(f_{61}\right)$, seizing $\left(f_{62}\right)$.

7. Material properties: aging $\left(f_{71}\right)$, hardening $\left(f_{72}\right)$.

In the next step, the primary root causes of failures were defined. The available literature [40] defines the following root causes: physical, human, and latent. For the vane pump, the primary root causes were set as follows:

1. Design/Specification $\left(o_{1}\right)$.

2. Material/Manufacturing $\left(o_{2}\right)$.

3. Assembly/Installation $\left(o_{3}\right)$.

4. Maintenance/Fluid $\left(o_{4}\right)$.

5. Operation: Overload $\left(o_{5}\right)$.

At this stage, the end effects that can occur as a results of individual failure were also identified:

1. Catastrophic: major damages with component destruction $\left(l_{1}\right)$.

2. Critical: component malfunction with severe damages $\left(l_{2}\right)$.

3. Marginal: component malfunction with minor damages $\left(l_{3}\right)$.

4. Minor: less than minor damages $\left(l_{4}\right)$.

Creating sheet.

To perform the analysis, the sheet presented in Figure 2 was created. It consists of the relationships between the components, failures, causes, and end effects. These relation are binary numbers, where (1) indicates that the relation is true and (0) indicates that it is false. 


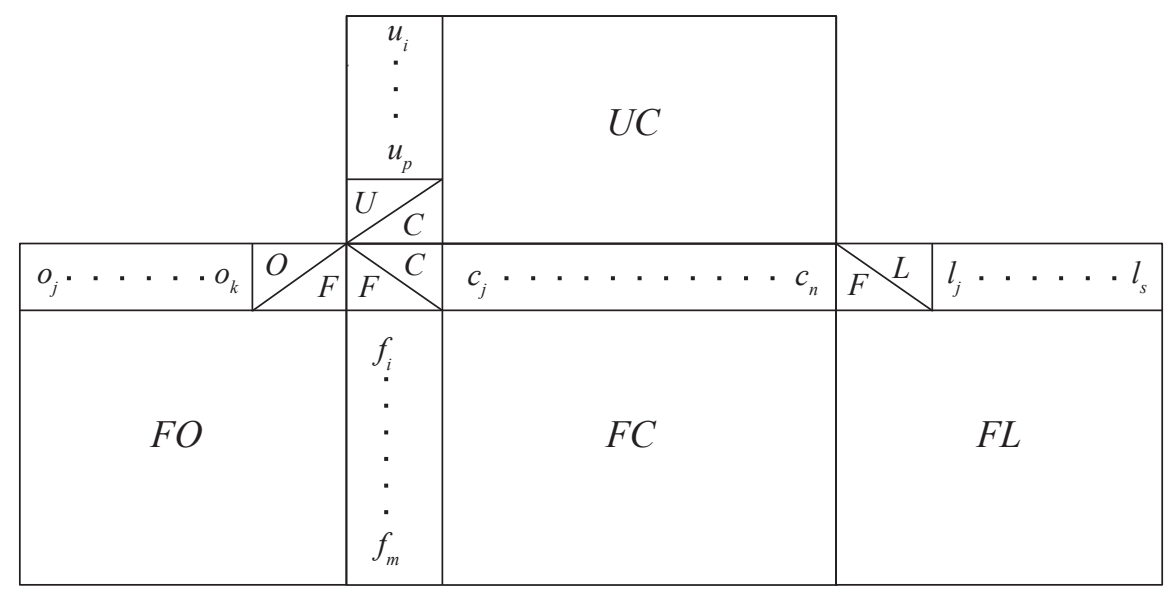

Figure 2. Sheet, $\mathrm{C}$-component, $\mathrm{U}$-component function, $\mathrm{O}$ - primary root causes, $\mathrm{L}$-end effect, FC-relation failure-component, UC-relation function-component, FO-relation failure-cause, FL-relation failure-end effect).

Analysis.

The data from Figure 2 (the sheet) can be presented as sets of components, failures, causes of failures, end effects, and functions of components. We can write these sets as follows:

Set of components $C$, where

$$
c_{j} \in C, j \in\{1 \ldots n\}
$$

Set of failures $F$, where

$$
f_{i} \in F, i \in\{1 \ldots m\}
$$

Set of causes of failures $O$, where

$$
o_{j} \in O, j \in\{1 \ldots k\}
$$

Set of end effects $L$, where

$$
l_{j} \in L, j \in\{1 \ldots s\}
$$

Set of end effects, $U$ where

$$
u_{j} \in U, j \in\{1 \ldots p\}
$$

We define the relationships between the listed sets. The relationship between the sets of failures $F$ and components $C$ can be defined as follows:

$$
R_{f c} \subseteq F \times C=\left\{\begin{array}{lc}
1, & \text { if failure occurs } \\
0, & \text { no failure. }
\end{array}\right.
$$

The relationship between the sets of failures $F$ and their causes $O$ can be defined as follows:

$$
R_{f_{0}} \subseteq F \times O=\left\{\begin{array}{lc}
1, & \text { if cause can make failure } \\
0, & \text { otherwise }
\end{array}\right.
$$

The relationship between the sets of failures $F$ and end effects $L$ can be defined as follows: 


$$
R_{f l} \subseteq F \times L=\left\{\begin{array}{cc}
1, & \text { if cause can make failure } \\
0, & \text { otherwise }
\end{array}\right.
$$

The relationship between the sets of components $C$ and their functions $U$ can be defined as follows:

$$
R_{\mathcal{C} u} \subseteq C \times U=\left\{\begin{array}{cc}
1, & \text { if component perform function } \\
0, & \text { otherwise }
\end{array}\right.
$$

The obtained matrices can be used to prioritize potential failures in the vane pump for the functions performed by the elements by multiplying the matrix $U C$ and the transposed matrix $F C^{T}$ :

$$
U F=U C \cdot F C^{T}
$$

The relationship between the causes of potential failures for individual components is obtained by multiplying the transposed matrix $F O^{T}$ and the matrix FC:

$$
O C=F O^{T} \cdot F C
$$

The relationship between the end effects inducted by failures and pump components is obtained by multiplying the transposed matrix $F L^{T}$ and the matrix $F C$ :

$$
L C=F L^{T} \cdot F C
$$

The relationship between the failure causes and the end effects is obtained by multiplying the transposed matrix $F L^{T}$ and the matrix $F O$ :

$$
L O=F L^{T} \cdot F O
$$

The relationship between components function and the end effects inducted by failures is obtained by multiplying the matrix $F U$ and the matrix FL:

$$
U L=F U \cdot F L
$$

The relationship between components function and the causes of failures is obtained as follows:

$$
U O=\left(U C \cdot F C^{T}\right) \cdot F L \cdot\left(F L^{T} \cdot F O\right)
$$

The values of elements of the matrices $O C, L C, U F, L O, U L$, and $U O$ can be written in the following general form:

$$
c_{i j}=\sum_{m=1}^{n} a_{i m} b_{m j}
$$

where $c_{i j}$ is the element of matrices OC, LC, UF, LO, UL, and $U O$, while $a_{i m}$ and $b_{m j}$ are elements of the multiplied matrices FC, UC, FO, and FL.

The created matrices can also be used to determine the impact of potential failures on the pump failure modes. For realization of this purpose, we can assume a kind of test vector that we can define as follows:

$$
\begin{gathered}
T=\left[t_{1}, \ldots, t_{n}\right] \\
t_{i} \subseteq T=\left\{\begin{array}{lc}
1, & \text { if failure occures } \\
0, & \text { otherwise }
\end{array}\right.
\end{gathered}
$$


where $t$ is the generalized failure for the $i$-th pump component, which belongs to set $C$.

Next, the Jaccard similarity index [34] is used for evaluating the influence of potential failure on given failure modes by measuring the similarity of test vector $T$ with a row of matrix FC:

$$
J\left(T, F_{i}\right)=\frac{\left|T \cap F_{i}\right|}{\left|T \cup F_{i}\right|}
$$

where $F_{i}$ is the $i$-th row of matrix FC.

\section{Results}

The sets of components, potential failures, causes, and end effects are expressed in the form presented below.

Set of components:

$$
C=\left[\begin{array}{llllllllllll}
c_{1} & c_{2} & c_{3} & c_{4} & c_{5} & c_{6} & c_{7} & c_{8} & c_{9} & c_{10} & c_{11} & c_{12}
\end{array}\right]
$$

Set of potential failures:

$$
F=\left[\begin{array}{lllllllllllllll}
f_{11} & f_{12} & f_{13} & f_{21} & f_{22} & f_{31} & f_{32} & f_{41} & f_{42} & f_{51} & f_{52} & f_{61} & f_{62} & f_{71} & f_{72}
\end{array}\right]
$$

Set of failure causes:

$$
O=\left[\begin{array}{lllll}
o_{1} & o_{2} & o_{3} & o_{4} & o_{5}
\end{array}\right]
$$

Set of components function:

$$
U=\left[\begin{array}{lll}
u_{1} & u_{2} & u_{3}
\end{array}\right]
$$

Set of end effects inducted by failures:

$$
L=\left[\begin{array}{llll}
l_{1} & l_{2} & l_{3} & l_{4}
\end{array}\right]
$$

Equation (6) gives matrix $F C$ :

$$
F C=\left[\begin{array}{llllllllllll}
1 & 1 & 1 & 1 & 1 & 0 & 0 & 0 & 0 & 1 & 1 & 1 \\
1 & 1 & 1 & 1 & 1 & 1 & 1 & 0 & 0 & 0 & 1 & 1 \\
0 & 0 & 1 & 1 & 1 & 0 & 1 & 0 & 0 & 0 & 0 & 0 \\
1 & 1 & 1 & 1 & 1 & 0 & 0 & 0 & 0 & 1 & 0 & 1 \\
0 & 0 & 0 & 0 & 0 & 0 & 0 & 0 & 1 & 0 & 0 & 0 \\
1 & 1 & 1 & 1 & 1 & 1 & 1 & 1 & 1 & 1 & 0 & 0 \\
1 & 1 & 1 & 1 & 1 & 1 & 1 & 1 & 0 & 0 & 0 & 0 \\
1 & 1 & 1 & 1 & 1 & 1 & 1 & 0 & 0 & 0 & 0 & 0 \\
1 & 1 & 1 & 1 & 1 & 1 & 1 & 0 & 0 & 0 & 0 & 0 \\
0 & 0 & 0 & 0 & 0 & 0 & 0 & 1 & 0 & 0 & 1 & 1 \\
1 & 1 & 1 & 1 & 1 & 1 & 1 & 1 & 0 & 1 & 1 & 0 \\
0 & 0 & 0 & 0 & 0 & 0 & 0 & 0 & 0 & 0 & 0 & 1 \\
0 & 0 & 1 & 0 & 1 & 1 & 1 & 1 & 0 & 0 & 0 & 0 \\
0 & 0 & 0 & 0 & 0 & 0 & 0 & 0 & 1 & 0 & 0 & 0 \\
0 & 0 & 0 & 0 & 0 & 0 & 0 & 0 & 1 & 0 & 0 & 0
\end{array}\right]
$$

Equation (7) gives matrix $F O$, while Equation (8) gives matrix $F L$ : 


$$
F O=\left[\begin{array}{lllll}
1 & 1 & 1 & 0 & 1 \\
1 & 1 & 0 & 0 & 0 \\
1 & 1 & 0 & 1 & 0 \\
1 & 1 & 1 & 0 & 1 \\
1 & 1 & 1 & 1 & 0 \\
0 & 0 & 0 & 1 & 0 \\
1 & 1 & 0 & 1 & 0 \\
0 & 0 & 0 & 1 & 0 \\
1 & 0 & 0 & 1 & 0 \\
1 & 1 & 0 & 0 & 0 \\
1 & 1 & 0 & 1 & 0 \\
1 & 1 & 1 & 0 & 0 \\
1 & 1 & 0 & 1 & 0 \\
1 & 1 & 0 & 1 & 0 \\
0 & 1 & 0 & 1 & 1
\end{array}\right] F L=\left[\begin{array}{llll}
1 & 1 & 1 & 1 \\
1 & 1 & 1 & 1 \\
0 & 0 & 1 & 1 \\
1 & 1 & 1 & 1 \\
1 & 1 & 1 & 1 \\
0 & 0 & 1 & 1 \\
0 & 0 & 1 & 1 \\
0 & 0 & 1 & 1 \\
0 & 0 & 1 & 1 \\
0 & 0 & 1 & 1 \\
0 & 0 & 1 & 1 \\
0 & 0 & 1 & 1 \\
0 & 0 & 1 & 1 \\
0 & 0 & 1 & 1 \\
0 & 0 & 1 & 1
\end{array}\right]
$$

Equation (9) gives matrix UC:

$$
U C=\left[\begin{array}{llllllllllll}
1 & 1 & 1 & 1 & 1 & 0 & 1 & 0 & 0 & 0 & 0 & 1 \\
0 & 0 & 0 & 0 & 0 & 1 & 1 & 1 & 0 & 0 & 0 & 0 \\
0 & 0 & 0 & 0 & 0 & 0 & 0 & 0 & 1 & 1 & 1 & 0
\end{array}\right]
$$

Equations (10)-(15) gives matrices $O C, L C, U F, L O, U L$, and $U O$, respectively.

The matrix UF describes the relationships between failures and pump components:

$$
U F=\left[\begin{array}{lllllllllllllll}
6 & 6 & 3 & 6 & 0 & 5 & 5 & 5 & 5 & 1 & 5 & 1 & 2 & 0 & 0 \\
0 & 2 & 1 & 0 & 1 & 4 & 3 & 2 & 2 & 1 & 3 & 0 & 3 & 1 & 1 \\
2 & 1 & 0 & 1 & 1 & 2 & 0 & 0 & 0 & 1 & 2 & 0 & 0 & 1 & 1
\end{array}\right]
$$

The matrix $O C$ describes the relationships between failure causes and pump components:

$$
O C=\left[\begin{array}{llllllllllll}
6 & 6 & 8 & 7 & 8 & 5 & 6 & 4 & 2 & 3 & 4 & 5 \\
5 & 5 & 7 & 6 & 7 & 4 & 5 & 4 & 3 & 3 & 4 & 5 \\
2 & 2 & 2 & 2 & 2 & 0 & 0 & 0 & 1 & 2 & 1 & 3 \\
5 & 5 & 7 & 6 & 7 & 6 & 7 & 4 & 4 & 2 & 1 & 0 \\
2 & 2 & 2 & 2 & 2 & 0 & 0 & 0 & 1 & 2 & 1 & 2
\end{array}\right]
$$

The matrix $L C$ describes the relationships between pump components and end effects:

$$
L C=\left[\begin{array}{cccccccccccc}
3 & 3 & 3 & 3 & 3 & 1 & 1 & 0 & 1 & 2 & 2 & 3 \\
3 & 3 & 3 & 3 & 3 & 1 & 1 & 0 & 1 & 2 & 2 & 3 \\
8 & 8 & 10 & 9 & 10 & 7 & 8 & 5 & 4 & 4 & 4 & 5 \\
8 & 8 & 10 & 9 & 10 & 7 & 8 & 5 & 4 & 4 & 4 & 5
\end{array}\right]
$$

The matrices $L O, U L$, and $U O$ describe the relationships between failure causes and end effects, component functions and end effects, and component functions and causes of failures, respectively.

$$
L O=\left[\begin{array}{ccccc}
4 & 4 & 3 & 1 & 2 \\
4 & 4 & 3 & 1 & 2 \\
12 & 12 & 4 & 10 & 3 \\
12 & 12 & 4 & 10 & 3
\end{array}\right] U L=\left[\begin{array}{cccc}
19 & 19 & 58 & 58 \\
2 & 2 & 20 & 20 \\
5 & 5 & 12 & 12
\end{array}\right] U O=\left[\begin{array}{ccccc}
1544 & 1544 & 578 & 1198 & 424 \\
496 & 496 & 172 & 404 & 128 \\
328 & 328 & 126 & 250 & 92
\end{array}\right]
$$

To evaluate the influence of defined failures on failure modes and prioritize failure, we can classify failure modes in the following ways [42]:

1. Critical, the pump does not realize the intended function (no flow on the pump outlet):

- Symptom: no shaft rotation $T_{1}$.

- Symptom: pump leakage $T_{2}$. 
2. Major, pump malfunction:

- $\quad$ Symptom: noisy operation $T_{3}$.

- Symptom: flow below rated $T_{4}$.

- Symptom: pressure below rated $T_{5}$.

3. Minor:

- Symptom: unusual heat level $T_{6}$.

- $\quad$ Symptom: shaft leaks $T_{7}$.

The tests vectors for the abovementioned symptoms are presented in (Table 1)

Table 1. Test vector values.

\begin{tabular}{lllllllllllll}
\hline & $c_{\mathbf{1}}$ & $c_{\mathbf{2}}$ & $c_{\mathbf{3}}$ & $c_{\mathbf{4}}$ & $c_{\mathbf{5}}$ & $\boldsymbol{c}_{\mathbf{6}}$ & $\boldsymbol{c}_{\mathbf{7}}$ & $c_{\mathbf{8}}$ & $c_{\mathbf{9}}$ & $c_{\mathbf{1 0}}$ & $c_{\mathbf{1 1}}$ & $c_{\mathbf{1 2}}$ \\
\hline$T_{1}$ & 1 & 0 & 1 & 1 & 1 & 0 & 1 & 0 & 0 & 0 & 0 & 0 \\
$T_{2}$ & 1 & 1 & 1 & 1 & 0 & 0 & 0 & 0 & 0 & 0 & 0 & 1 \\
$T_{3}$ & 0 & 0 & 1 & 1 & 1 & 1 & 1 & 0 & 0 & 1 & 0 & 0 \\
$T_{4}$ & 0 & 0 & 0 & 1 & 1 & 1 & 0 & 1 & 1 & 0 & 0 & 0 \\
$T_{5}$ & 0 & 0 & 0 & 1 & 1 & 1 & 0 & 0 & 0 & 0 & 0 & 0 \\
$T_{6}$ & 0 & 0 & 1 & 1 & 1 & 1 & 1 & 0 & 0 & 0 & 0 & 0 \\
$T_{7}$ & 0 & 0 & 1 & 0 & 0 & 0 & 0 & 0 & 1 & 0 & 0 & 0 \\
\hline
\end{tabular}

Discussion.

The results presented in the above section allow for the classification of failures and their causes depending on the user's needs. Let us assume that, as in a typical FMEA, we are interested in prioritizing failures. Using the matrix UF Equation (28), we can determine the failures that occur most often for the functions performed by the pump components. Taking into account the end effects, we can classify the failures as follows:

1. Brittle fracture $\left(f_{11}\right)$, fatigue fracture $\left(f_{12}\right)$, yielding $\left(f_{21}\right)$.

2. Abrrasive wear $\left(f_{31}\right)$, adhesive wear $\left(f_{32}\right)$, particles erosion $\left(f_{41}\right)$, cavitaion erosion $\left(f_{42}\right)$, chemical attack $\left(f_{52}\right)$.

3. Pitting $\left(f_{13}\right)$.

4. Seizing $\left(f_{62}\right)$.

5. Aging $\left(f_{71}\right)$, hardening $\left(f_{72}\right)$.

Analysis of the matrix OC in Equation (29) shows that the dominant causes of failures are as follows:

1. Design $\left(o_{1}\right)$ for shaft $\left(c_{3}\right)$ and vane $\left(c_{5}\right)$.

2. Maintenance/Fluid $\left(o_{4}\right)$ for shaft $\left(c_{3}\right)$, vane $\left(c_{5}\right)$ and bearing $\left(c_{7}\right)$.

3. Material/Manufacturing $\left(o_{2}\right)$ for stator $\left(c_{4}\right)$, shaft $\left(c_{3}\right)$.

4. Assembly/Installation $\left(o_{3}\right)$ for fastener $\left(c_{12}\right)$.

5. Operation: Overload $\left(o_{5}\right)$ for housing $\left(c_{1}\right)$, cover $\left(c_{2}\right)$, shaft $\left(c_{3}\right)$, stator $\left(c_{4}\right)$, vane $\left(c_{5}\right)$, pin $\left(c_{10}\right)$, and fastener $\left(c_{12}\right)$.

The matrix $L C$ in Equation (30) indicates that, for given failures, the pump component end effects are marginal $\left(l_{3}\right)$ and minor $\left(l_{4}\right)$.

We can use the matrix $L C$ in Equation (31) prioritize causes of failures for given end effects. For example for end effects: Catastrophic $\left(l_{1}\right)$ and Critical $\left(l_{2}\right)$, these causes are as follows:

1. Design $\left(o_{1}\right)$, Material/Manufacturing $\left(o_{2}\right)$.

2. Assembly/Installation $\left(o_{3}\right)$.

3. Operation: Overload $\left(o_{5}\right)$.

4. Maintenance/Fluid $\left(o_{4}\right)$.

In the similar way, we can obtain causes of failures for end effects marginal $\left(l_{3}\right)$ and minor $\left(l_{4}\right)$, which are

1. Design $\left(o_{1}\right)$, Material/Manufacturing $\left(o_{2}\right)$. 
2. Maintenance/Fluid $\left(o_{4}\right)$.

3. Assembly/Installation $\left(o_{3}\right)$.

4. Operation: Overload $\left(o_{5}\right)$.

Causes of failures for given component functions can be obtained from matrix $U O$ in Equation (31) and they are:

1. Design $\left(o_{1}\right)$, Material/Manufacturing $\left(o_{2}\right)$.

2. Maintenance/Fluid $\left(o_{4}\right)$.

3. Assembly/Installation $\left(o_{3}\right)$.

4. Operation: Overload $\left(O_{5}\right)$.

Matrix $U L$ in Equation (31) indicates that potential failures make end effects marginal $\left(l_{3}\right)$ and minor $\left(l_{4}\right)$ for components performing functions $\left(u_{1}\right),\left(u_{2}\right)$, and $\left(u_{3}\right)$, but it has to be added that the analyzed failures are the primary ones that can be an initiating factor for other types of failures. The obtained results from Equation (29) agree with wellknown quality management rules that nearly $80 \%$ of failures are caused at the conceptual and design stages. According to the presented method, maintenance/fluid is the major cause of failures for vane pumps, which is also confirmed in practice [29]. An additional confirmation factor is that the vane pumps are used as reference devices for standardized validation tests [43-45] for evaluating the quality of working fluids.

The Jaccard similarity index (Table 2) shows the influence of individual failures on failure modes. For critical failure modes, the dominant failures are brittle fracture $\left(f_{11}\right)$, fatigue fracture $\left(f_{12}\right)$, yielding $\left(f_{21}\right)$, abrasive wear $\left(f_{31}\right)$, adhesive wear $\left(f_{32}\right)$, particles erosion $\left(f_{41}\right)$, cavitation erosion $\left(f_{42}\right)$, and chemical attack $\left(f_{52}\right)$. For major failure modes, the dominant failure are abrasive wear $\left(f_{31}\right)$ and chemical attack $\left(f_{52}\right)$, while for minor failure modes, the following failures are dominant: yielding $\left(f_{21}\right)$, abrasive wear $\left(f_{31}\right)$, adhesive wear $\left(f_{32}\right)$, particles erosion $\left(f_{41}\right)$, cavitation erosion $\left(f_{42}\right)$, and chemical attack $\left(f_{52}\right)$.

The obtained results agree with the empirical data included in [29], which is a compendium of vane pump and motor failures and their causes. The main failures according to [29] for pump components that perform main functions (shaft, stator, and rotor) are fatigue rupture (shaft) and brittle rupture (rotor and stator). The Jaccard similarity index (Table 2) indicates the same failures. It has to be mentioned that other failures presented in the table such as abrasive wear, particle erosion, and cavitation erosion can also be initiators of fatigue crack. The data from the table also agree with the results from UF in Equation (28), which defines the failures for components performing main functions. Noisy pump operation according to [29] is mainly caused by oil aeration and/or cavitation. This leads to wear of port plates or vanes. The Jaccard similarity index (Table 2) for failure mode noisy operation shows also abrasive wear as a dominant failure.

Table 2. The Jaccard similarity index for test vectors and failures.

\begin{tabular}{llllllllllllllll}
\hline & $f_{\mathbf{1 1}}$ & $f_{\mathbf{1 2}}$ & $f_{\mathbf{1 3}}$ & $f_{\mathbf{2 1}}$ & $f_{\mathbf{2 2}}$ & $f_{\mathbf{3 1}}$ & $f_{\mathbf{3 2}}$ & $f_{\mathbf{4 1}}$ & $f_{\mathbf{4 2}}$ & $f_{\mathbf{5 1}}$ & $f_{\mathbf{5 2}}$ & $f_{\mathbf{6 1}}$ & $f_{\mathbf{6 2}}$ & $f_{\mathbf{7 1}}$ & $f_{\mathbf{7 2}}$ \\
\hline$T_{1}$ & 0.33 & 0.42 & 0.33 & 0.33 & 0.00 & 0.42 & 0.42 & 0.42 & 0.42 & 0.00 & 0.42 & 0.00 & 0.25 & 0.00 & 0.00 \\
$T_{2}$ & 0.42 & 0.42 & 0.17 & 0.42 & 0.00 & 0.33 & 0.33 & 0.33 & 0.33 & 0.08 & 0.33 & 0.08 & 0.08 & 0.00 & 0.00 \\
$T_{3}$ & 0.33 & 0.42 & 0.33 & 0.33 & 0.00 & 0.50 & 0.42 & 0.42 & 0.42 & 0.00 & 0.50 & 0.00 & 0.33 & 0.00 & 0.00 \\
$T_{4}$ & 0.17 & 0.25 & 0.17 & 0.17 & 0.08 & 0.42 & 0.33 & 0.25 & 0.25 & 0.08 & 0.33 & 0.00 & 0.25 & 0.08 & 0.08 \\
$T_{5}$ & 0.17 & 0.25 & 0.17 & 0.17 & 0.00 & 0.25 & 0.25 & 0.25 & 0.25 & 0.00 & 0.25 & 0.00 & 0.17 & 0.00 & 0.00 \\
$T_{6}$ & 0.25 & 0.42 & 0.33 & 0.25 & 0.00 & 0.42 & 0.42 & 0.42 & 0.42 & 0.00 & 0.42 & 0.00 & 0.33 & 0.00 & 0.00 \\
$T_{7}$ & 0.08 & 0.08 & 0.08 & 0.08 & 0.08 & 0.17 & 0.08 & 0.08 & 0.08 & 0.00 & 0.08 & 0.00 & 0.08 & 0.08 & 0.08 \\
\hline
\end{tabular}

\section{Conclusions}

The presented method uses the matrix analysis along with elements of statistics that allows for the classification of potential failures and their causes in relation to the end effects inducted by the failures and to component functions. It also allows for performing select elements of RCA analysis. The proposed practical sheet allows for preparing data and its initial classification before they are used at the analysis stage. This sheet can be 
extended and adapted to the existing needs. The application of a similarity index allows for the identification of contribution to a specified pump failure mode. The presented method allows for identification failures, which refers to critical, major, and minor failure modes. The obtained results can be input data for further analysis aimed at searching for root cause of failures and at defining preventative measures. The presented method is simple for algorithmization and can be extended using elements of a statistical tool or matrix analysis. The method can also be used to analyze hydraulics components as well as full hydraulic systems.

Author Contributions: Conceptualization, J.F.-D. and M.D.; methodology, J.F.-D.; software, H.M.; validation, M.D., J.F.-D., and H.M.; formal analysis, J.F.-D.; investigation, J.F.-D.; resources, J.F.-D.; data curation, M.D.; writing—original draft preparation, M.D.; writing-review and editing, H.M.; visualization, H.M.; supervision, M.D.; project administration, J.F.-D.; funding acquisition, H.M. All authors have read and agreed to the published version of the manuscript.

Funding: This research received no external funding.

Institutional Review Board Statement: Not applicable.

Informed Consent Statement: Not applicable.

Data Availability Statement: Not applicable.

Conflicts of Interest: The authors declare no conflict of interest.

\begin{tabular}{|c|c|}
\hline \multicolumn{2}{|c|}{ Abbreviations } \\
\hline \multicolumn{2}{|c|}{ The following abbreviations are used in this manuscript: } \\
\hline \multicolumn{2}{|c|}{ MDI } \\
\hline \\
\hline \multicolumn{2}{|r|}{ fense Standard } \\
\hline FMEA & Failure Modes and Effect Analysis \\
\hline \multicolumn{2}{|l|}{ FMEDA } \\
\hline & Failure Modes, Effects, and Criticality Analysis \\
\hline NASA & National Aeronautics and Space Administration \\
\hline $\mathrm{RCA}$ & Root Cause Analysis \\
\hline \multirow{2}{*}{$\begin{array}{l}\text { RPN } \\
\text { ISO }\end{array}$} & Risk Priority Number \\
\hline & International Organization for Standardization \\
\hline
\end{tabular}

\section{References}

1. Lee, Y.; Lee, G.; Yang, J.; Park, J.; Baek, D. Failure analysis of a hydraulic power system in the wind turbine. Eng. Fail. Anal. 2020, 107, 104218. [CrossRef]

2. Li, Y.; Coolen, F.P.A.; Zhu, C.; Tan, J. Reliability assessment of the hydraulic system of wind turbines based on load-sharing using survival signature. Renew. Energy 2020, 153, 766-776. [CrossRef]

3. Gao, P.; Yu, T.; Zhang, Y.; Wang, J.; Zhai, J. Vibration analysis and control technologies of hydraulic pipeline system in aircraft: A review. Chin. J. Aeronaut. 2020, 34, 83-114. [CrossRef]

4. Wang, G.; Song, Y.; Wang, J.; Chen, W.; Cao, Y.; Wang, J. Study on the Shifting Quality of the CVT Tractor under Hydraulic System Failure. Appl. Sci. 2020, 10, 681. [CrossRef]

5. Ma, Z.; Wang, S.; Shi, J.; Li, T.; Wang, X. Fault diagnosis of an intelligent hydraulic pump based on a nonlinear unknown input observer. Chin. J. Aeronaut. 2018, 31, 385-394. [CrossRef]

6. Li, T.; Wang, S.; Zio, E.; Shi, J.; Ma, Z. A numerical approach for predicting the remaining useful life of an aviation hydraulic pump based on monitoring abrasive debris generation. Mech. Syst. Signal Process. 2018, 136, 106519. [CrossRef]

7. Hast, D.; Findeisen, R.; Streif, S. Detection and isolation of parametric faults in hydraulic pumps using a set-based approach and quantitative-qualitative fault specifications. Control Eng. Pract. 2015, 40, 61-70. [CrossRef]

8. Lu, C.; Wang, S.; Wang, X. A multi-source information fusion fault diagnosis for aviation hydraulic pump based on the new evidence similarity distance. Aerosp. Sci. Technol. 2017, 71, 392-401. [CrossRef]

9. Tague, N.R. The Quality Toolbox, 2nd ed.; ASQ Quality Press: Milwaukee, WI, USA, 2005.

10. Carlson, C.S. Effective FMEAs: Achieving Safe, Reliable, and Economical Products and Processes Using Failure Mode and Effects Analysis; John Wiley \& Sons, Inc.: Hoboken, NJ, USA, 2012. 
11. Byington, C.S.; Roemer, M.J.; Galie, T. Prognostic enhancements to diagnostic systems for improved condition-based maintenance [military aircraft]. In Proceedings of the IEEE Aerospace Conference, Big Sky, MT, USA, 9-16 March 2002.

12. Tidriri, K.; Chatti, N.; Verron, S.; Tiplica, T. Bridging data-driven and model-based approaches for process fault diagnosis and health monitoring: A review of researches and future challenges. Annu. Rev. Control 2016. [CrossRef]

13. Djeziri, M.A.; Benmoussa, S.; Zio, E. Review on Health Indices Extraction and Trend Modeling for Remaining Useful Life Estimation. In Artificial Intelligence Techniques for a Scalable Energy Transition; Sayed-Mouchaweh, M., Ed.; Springer: Berlin, Germany, 2020.

14. MIL-P 1629. USA Military Standard, Procedure for Performing a Failure Mode, Effects and Criticality Analysis (MIL-P 1629, USA); Military Specifications and Standards: Washington, DC, USA, 1949.

15. J1739 200901. Potential Failure Mode and Effects Analysis in Design (Design FMEA), Potential Failure Mode and Effects Analysis in Manufacturing and Assembly Processes (Process FMEA); SAE International J1739 200901: Warrendale, PA, USA, 2009.

16. Grebe, J.C.; Goble, W.M. FMEDA-Accurate Product Failure Metrics, FMEDA Development Paper; Revision 1.1, 19 February 2007; FMEDA: Exida, PA, USA, 2007.

17. IEC 61508. Functional Safety of Electrical/Electronic/Programmable Electronic Safety-Related Systems; International Electrotechnical Commission, IEC 61508: Geneva, Switzerland, 2010.

18. Globe, W.M.; Bukowski, J.V. Development of a Mechanical Component Failure Database. In Proceedings of the annual Reliability and Maintainability Symposium, Orlando, FL, USA, 22-25 January 2007.

19. Wirth, R.; Berthold, B.; Kramer, A.; Peter, G. Knowledge-based Support Analysis for the Analysis of Failure Modes and Effects. Eng. Appl. Artif. Intell. 1996, 9, 219-229. [CrossRef]

20. Liu, H.C.; Liu, L.; Liu, N. Risk evaluation approaches in failure mode and effects analysis: A literature review. Expert Syst. Appl. 2013, 40, 828-838. [CrossRef]

21. Liu, H.-C. FMEA Using Uncertainty Theories and MCDM Methods; Springer Science+Business Media: Singapore, 2016.

22. Liu, H.C.; Liu, L.; Bian, Q.H.; Lin, Q.L.; Dong, N.; Xu, P.C. Failure mode and effects analysis using fuzzy evidential reasoning approach and grey theory. Expert Syst Appl. 2011, 38, 4403-4415. [CrossRef]

23. Bahrebar, S.; Blaabjerg, F.; Wang, H.; Vafamand, N.; Khooban, M.H.; Rastayesh, S.; Zhou, D. A Novel Type-2 Fuzzy Logic for Improved Risk Analysis of Proton Exchange Membrane Fuel Cells in Marine Power Systems Application. Energies 2018, 11, 721. [CrossRef]

24. Liu, S.; Guo, X.; Zhang, L. An Improved Assessment Method for FMEA for a Shipboard Integrated Electric Propulsion System Using Fuzzy Logic and DEMATEL Theory. Energies 2019, 12, 3162. [CrossRef]

25. Lv, Y.; Liu, Y.; Jing, W.; Wozniak, M.; Damasevicius, R.; Scherer, R.; Wei, W. Quality Control of the Continuous Hot Pressing Process of Medium Density Fiberboard Using Fuzzy Failure Mode and Effects Analysis. Appl. Sci. 2020, 10, 4627. [CrossRef]

26. Filo, G.; Fabis-Domagala, J.; Domagala, M.; Lisowski, E.; Momeni, H. Knowledge-based Support Analysis for the Analysis of Failure Modes and Effects. MATEC Web Conf. 2018, 183, 03009. [CrossRef]

27. AIAG \& VDA FMEA Handbook; Automotive Industry Action Group (AIAG): Southfield, MI, USA, 2019.

28. Watton, J. Modelling, Monitoring and Diagnostic Techniques for Fluid Power Systems; Springer: London, UK, 2007.

29. Catalogue HY29-0022/UK, 2M, 01/2012, IRO; Parker Hannifin Corporation, Parker Hannifin Limited: Warwick, UK, 2014.

30. Barbour, G.L. Failure Modes and Effects Analysis by Matrix Method. In Proceedings of the Annual Reliability Symposium, Philadelphia, PA, USA, 18-20 January 1977; pp. 114-119.

31. Stock, M.E.; Stone, R.B.; Tumer, I.Y. Going back in time to improve design: The elemental function-failure design method. In Proceedings of the DETC 03 ASME 2003 Design Engineering Technical Conference Computers and Information in Engineering Conference, Chicago, IL, USA, 2-6 September 2003.

32. Arunajadai, S.G.; Uder, S.J.; Stone, R.B.; Tumer, I.Y. Failure Mode Identification through Clustering Analysis. Qual. Reliab. Eng. Int. 2004, 20, 511-526. [CrossRef]

33. Wilson, P.F.; Dell, L.D.; Anderson, G.F. Root Cause Analysis: A Tool for Total Quality Management; ASQ Quality Press: Milwaukee, WI, USA, 1993.

34. Jaccard, P. Etude comparative de la distribution florale dans une portion des Alpes et du Jura. Bull. Soc. Vaudoise Des Sci. Nat. 1901, 37. [CrossRef]

35. McDermott, R.E.; Mikulak, R.J.; Beauregard, M.R. The Basics of FMEA, 2nd ed.; CRC Press: New York, NY, USA, 2009.

36. Bloch, H.P.; Geitner, F.K. Machinery Failure Analysis and Troubleshooting; Gulf Professional Publishing: Huston, TX, USA, 1999; Volume 2 .

37. Stachowiak, G.W. Wear-Materials, Mechanism and Practice; John Wiley \& Sons Ltd.: Chichester, UK, 2005.

38. Kato, K. Classification of wear mechanisms/models. J. Eng. Tribol. 2002, 216. [CrossRef]

39. Donald, J.; Wulpi, L. Understanding How Components Fail, 3rd ed.; Miller, B., Ed.; ASM International: Materials Park, OH, USA, 2013.

40. Hossain, F.A.; Scutti, J.J. Four Fundamental Root Causes of Failure: Case Histories, Failure Analysis: A Foundation for Diagnostics and Prognostics Development. In Proceedings of the 53rd Meeting of Society for Machinery Failure Prevention Technology, Virginia Beach, VA, USA, 19-22 April 1999.

41. Flitney, R. Seals and Sealing Handbook, 6th ed.; Butterworth-Heinemann: Oxford, UK, 2014.

42. Bulletin HY29-0106/UK, XM, 08/2012; Parker Hannifin Manufacturing France SAS: Vierzon Cedex, France, 2012. 
43. ASTM D7043-17. Standard Test Method for Indicating Wear Characteristics of Non-Petroleum and Petroleum Hydraulic Fluids in a Constant Volume Vane Pump; ASTM International: West Conshohocken, PA, USA, 2017.

44. DIN 51389-1. Determination of Lubricants; Mechanical Testing of Hydraulic Fluids in the Vane-Cell-Pump; General Working Principles; DIN Deutsches Institut für Normung e. V.: Berlin, Germany, 1982.

45. ISO 20763:2004. Petroleum and Related Products—Determination of Anti-Wear Properties of Hydraulic Fluids-Vane Pump Method; International Organization for Standardization: Geneva, Switzerland, 2004. 